\title{
Leader-Member Exchange Theory in Higher and Distance Education
}

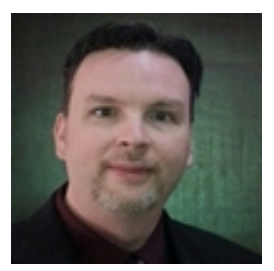

Robert Leo Power

College of the North Atlantic-Qatar, Qatar

\section{Abstract}

Unlike many other prominent leadership theories, leader-member exchange (LMX) theory does not focus on the specific characteristics of an effective organizational leader. Rather, LMX focuses on the nature and quality of the relationships between a leader and his or her individual subordinates. The ideal is for a leader to develop as many high-quality relationships as possible. This will lead to increases in subordinates' sense of job satisfaction and organizational citizenship, as well as to increased productivity and attainment of organizational goals. LMX has been criticized for its potential to alienate some subordinates, failing to account for the effects of group dynamics and social identity, and failing to provide specific advice on how leaders can develop highquality relationships. However, LMX has been heralded as an important leadership theory in higher and distance educational contexts because of its emphasis on promoting autonomy and citizenship, as well as its ability to complement and mediate transformational leadership styles. Recent authors have attempted to provide specific advice for leaders who want to learn how to build and capitalize on the high-quality relationships described by LMX theory.

Keywords: Distance education; higher education; leader-member exchange theory; leadership; LMX; open and distance learning; social identity theory of leadership 


\section{Leader-Member Exchange Theory in Higher and Distance Education}

In recent years criticism has been leveled on higher education systems in North America, as well as other parts of the world, for their perceived failure to transform themselves to meet the changing needs of society (Keller, 2008; Latchem \& Hanna, 2001). Much of that criticism focuses on perceptions of stubborn adherence to outdated business models, lack of accessibility for key segments of the population, and failure to adopt technological and pedagogical innovations that will better serve the needs of learners. To this end, there has been a recent focus on transformational leadership amongst educational researchers and writers from around the globe. However, calls for the promotion of leaders with transformative visions, by themselves, are not enough to provide the type of leadership needed in higher and distance education today (Graen \& Uhl-Bien, 1996). What is needed is a shift away from a preoccupation with the characteristics of effective leaders, and a focus on the behaviors of those leaders that will inspire others to follow them towards the transformation of higher education. An understanding of how effective higher and distance education leaders behave in relation to their followers can be found in leader-member exchange (LMX) theory. LMX has been described as a perfect complement to transformational leadership because of its support for the autonomous nature of academic faculty and its ability to create social capital, act as an antecedent to organizational citizenship and transformative behaviors, and promote higher quality relationships between coworkers. Leaders who want to inspire others to participate in the transformation of higher education must have a good understanding of LMX theory and its benefits. Likewise, they must be aware of its criticisms in order to avoid what some have described as potential flaws in LMX theory as a guide for effective leadership.

\section{The Impact of Leader-Member Exchange Theory}

Leader-member exchange theory (LMX) represents a departure from common leadership theories. Most theories focus on the characteristics of effective leaders. In contrast, LMX focuses on the relationships, which may be affected by personal characteristics, between leaders and followers (Graen \& Uhl-Bien, 1996; Truckenbrodt, 2000). Graen and Uhl-Bien (1996) impart a sense of urgency to look beyond the traits of effective leaders by describing a taxonomy of leadership with multiple domains including the leader, the follower, and the dyadic relationship. They warn that focusing on only one domain could result in flawed research designs and understandings of effective leadership. LMX brings the follower and relationship domains into the foreground of research alongside the study of such leadership styles as transformational leadership.

The central concept of LMX is that leadership is more effective when "leaders and followers are able to develop mature [partnerships] and thus gain access to the many 
benefits these relationships bring" (Graen \& Uhl-Bien, 1996, p. 225). LMX focuses on the dyadic relationship between leaders and individual followers, as opposed to the organizational group (Lunenburg, 2010; Truckenbrodt, 2000). Relationships are different with each follower, with some being of higher quality than others. Followers in high-quality relationships are part of an "in-group," while those experiencing lower quality relationships are "out-group" members (Lunenburg, 2010). In-group followers enjoy increased job latitude, more open communications, and greater confidence from leaders. This often results in reciprocation from in-group followers, who assume "greater responsibility, and commitment to the success of the organization" (p. 2). Relationships with out-group members are typically governed "within the narrow limits of their formal employment contract" (p. 2). Leaders who understand the significance of LMX are empowered with the understanding that they need to avoid the creation of out-groups wherever possible, and maximize the size of the in-group upon which they can rely.

Lunenburg (2010) presents findings that validate the implications of LMX for organizational effectiveness. He demonstrates that leaders do differentiate between followers, and this differentiation is not random. Such distinctions are not desirable, and leaders should strive to maximize the number of high-quality relationships they develop with their followers. This is because out-group members may grow to resent their apparent "inferior" status, experience more stress, and be less committed to overall organizational success. In contrast, followers in high-quality LMX relationships demonstrate organizational commitment beyond contractual obligations, and develop a sense of citizenship that can be vital to promoting dramatic organizational change. UhlBien (2003) describes how high-quality dyadic relationships enable the recognition and leveraging of the skills of the right people when those resources are needed. The relational focus of LMX can also help in identifying the right people to act as emerging leaders within an organization because it

recognizes leadership wherever it occurs, is not restricted to a single or even small set of formal or informal leaders, and in its strongest form, functions as a dynamic system embedding leadership, environmental, and organizational aspects (Hunt \& Dodge, 2001, in UhlBien, 2003, p. 129).

Developing effective relationships, and identifying the right people for critical roles within an organization requires an understanding of how followers interact with each other, and with organizational leaders, in their daily routines. Academics have frequently been described as highly autonomous (Latchem \& Hanna, 2001), which adds impetus to the importance of leaders developing high quality relationships on an individual basis. Academic faculty have high levels of expertise in their particular fields, and can be very passionate about issues and tasks in which they have a professional interest or stake. High quality LMX relationships can enable leaders to identify the 
passions of individual academic faculty, and then draw upon these passions to foster a sense of organizational citizenship and transformative collaboration.

Graen and Uhl-Bien (1996) highlight the connection between LMX and creating transformative collaboration. They describe LMX as both transactional and transformational, noting that the evolution of highly effective relationships results in the emergence of transformative behaviors for both parties. Wang et al. (2005) provide evidence for this assertion in their study of LMX as a mediator for transformational leadership in organizations throughout China. They describe transformational leadership behaviors as social currency that effect stronger dyadic relationships. They also correlate transformational leaders' high-quality LMX relationships with more effective task performance, increased organizational citizenship behaviors, and increased willingness amongst followers to take on extra roles and change how they do their jobs. According to Wang et al. (2005, p. 429), "LMX makes transformational leadership more personally meaningful" for the follower. Wang et al.'s findings are consistent with Truckenbrodt (2000), who found that high-quality LMX relationships are antecedents for increased organizational commitment and both altruistic and compliant organizational citizenship behaviors. Sherony and Green (2002) emphasize the danger of not fostering high-quality LMX relationships as widely across an organization as possible. They note that the diversity in the LMX relationships of coworkers and their leaders is predictive of scores when examining coworker exchanges (CWX), and that too much diversity in coworkers' relationships can have a negative impact upon job performance and organizational commitment.

\section{Addressing Criticisms of Leader-Member Exchange Theory}

Recognizing the potential for LMX to help lead effective transformations within higher and distance education organizations requires an understanding of its criticisms and potential flaws as a leadership theory. Identifying criticisms will enable leaders to make proactive decisions about the appropriateness of LMX in their own contexts, and to avoid potential flaws that may result in counterproductive leadership.

A web search of the term LMX turns up numerous supporting and detracting sites. Management Study Guide (2012), which offers leadership training programs, lists LMX's two main weak points as the alienation of out-group subordinates and failure to explain how to develop high-quality relationships. Lunenburg (2010) acknowledges the claim that low-quality dyadic relationships lead to resentment amongst some followers. However, as previously noted, leaders who prescribe to LMX should be aware of the dangers of potentially alienating some followers. These leaders should strive to minimize the number of out-group followers within the organization by developing as many high quality dyadic relationships as possible. 
Uhl-Bien (2003) recognizes the claim made by Management Style Guide (2012) of a lack of guidance on relationship development, noting that "a question that needs to be addressed is...what leads to development of higher and lower quality work relationships (e.g., antecedents to LMX)" (p. 130). If LMX is to be used to help understand how transformational leaders are to affect necessary changes in higher and distance education, then an understanding of how to nurture high-quality dyadic relationships is essential. While the lack of such guidance has been cited as a criticism of LMX (Hogg et al., 2005; Management Study Guide, 2012; Uhl-Bien, 2003), a wealth of advice can be found in the work of several recent authors. For instance, Lunenburg (2010, pp. 3-4) cites a number of tips from Krietner and Keninki (2010), and provides a detailed outline of five distinct stages in the development of high-quality relationships. The stages described by Lunenburg involve building upon a sense of mutual trust between leaders and followers. This trust and reciprocating collaboration eventually advances beyond self-interest for either party, and into a relationship based upon both clear role expectations and shared "commitment to the vision, mission and objectives" of the organization (p. 3). When that vision, mission and objectives entails adoption of education innovation and the transformation of institutional structures, following the stages and tips outlined by Lunenburg can help to make such transformations personally meaningful for all parties (Wang et al., 2005) and spread the sense of organizational commitment as far throughout the institution as possible.

Hogg, Martin, Epitropaki, Mankad, Svensson, and Weeden (2005) present another criticism of LMX as its failure to consider the wider social context in which organizational leadership occurs. They outline two organizational case studies where social identity theory of leadership more accurately predicted the leadership styles that would be favored by followers. Hogg et al. claim that LMX predicts followers will favor leaders who show a highly personalized interactive style. However, an exploration of the effects of group identity in Scottish and Indian business and industrial organizations demonstrated favor for a highly depersonalized leadership style, where leaders were recognized for practicing less favoritism, and regarded as more fair and equitable.

Hogg et al.'s (2005) studies are based in business and industrial cultures. The assertion that followers will prefer a depersonalized, equitable leader is premised on the primacy of group identity amongst individual employees. However, as previously noted, academics are frequently described as highly autonomous (Latchem \& Hanna, 2001), and LMX does present an appropriate theory for describing effective working relationships in higher and distance education institutions. Additionally, a follower's personal preference for a depersonalized leadership style does not negate the significance of LMX. Leaders who draw upon LMX are more able to identify the type of relationship and amount of direct leadership desired by each follower, and are able to tailor their individual leader-follower relationships accordingly. Graen and Uhl-Bien (1996) acknowledge that LMX focuses on individual dyadic relationships for the sake of simplicity. They also note that within complex organizations, leaders often interact with multiple followers "working together in some type of interacting collectivity" (p. 233), 
and that LMX should be further examined within the context of network assemblies in order to paint a more complete picture of effective organizational leadership.

\section{Conclusions}

Leader-member exchange (LMX) theory belongs to one of the first described taxonomies of domains of leadership and, as such, is significant for anyone wanting to understand how to implement effective leadership. LMX is significant in higher and distance education leadership contexts because of its close correlation with transformational leadership, which has gained recent prominence due to the frequently expressed need to transform institutions of higher learning to meet the changing demands of society. While LMX has been criticized for failing to account for group dynamics, prominent LMX researchers and writers have described the coexistence of complex collectives, or network assemblies, within the domains necessary to gain a complete picture of effective leadership. In addition, arguments based on the primacy of group dynamics and social identity may not be appropriate within the context of leadership in education, where followers are routinely afforded, and enjoy, a sense of relative autonomy. Instead, LMX offers insight into how high-quality leader-follower relationships mediate, and act as an antecedent to, transformative behaviors within organizations. Concerns that LMX is an incomplete leadership theory because of a lack of guidance on how to foster high-quality dyadic relationships have also been allayed by specific advice and tips provided by recent researchers and authors. While LMX does not present a complete understanding of effective leadership, it provides insight into a crucial domain of leadership that must be understood alongside leadership theories and strategies that focus on the traits and behaviors of individual leaders. 


\section{References}

Graen, G., \&Uhl-Bien, M. (1996). Relationship-based approach to leadership: Development of leader-member exchange (LMX) theory of leadership over 25 years: Applying a multi-level multi-domain perspective. The Leadership Quarterly, 6(2), 219-247. DOI: 10.1016/ 1048-9843(95)90036-5.

Hogg, M. A., Martin, R., Epitropaki, O., Mankad, A., Svensson, A., \& Weeden, K. (2005). Effective leadership in salient groups: Revisiting leader-member exchange theory from the perspective of the social identity theory of leadership. Personality and Social Psychology Bulletin, 31(7), 991-1004.

Latchem, C., \& Hanna, D (2001). Leadership for 21st century learning: Global perspectives from educational innovators. New York: Routledge.

Lunenburg, F. (2010). Leader-member exchange theory: Another perspective on the leadership process. International J ournal of Management, Business and Administration, 13(1), 1-5. Retrieved from http:// www.nationalforum.com/Electronic\%20J ournal\%20Volumes/Lunenbur g,\%20Fred\%20C.\%20LeaderMember\%20Exchange\%20Theory\%20IJ MBA\%20V13\%202010.pdf

Management Study Guide (2012). Leader-member exchange (LMX) theory. Retrieved from http:// managementstudyguide.com/lmx-theory.htm

Sherony, K., \& Green, S. (2002). Coworker exchange: Relationships between coworkers, leader-member exchange, and work attitudes. J ournal of Applied Psychology, 87(3), 542-548. DOI: 10.1037/0021-9010.87.3.542

Truckenbrodt, Y. (2000). The relationship between leader-member exchange and commitment and organizational citizenship behavior. Acquisition Review Quarterly-Summer 2000, 233-244. Retrieved from http:// www.au.af.mil/au/awc/awcgate/ dau/truck.pdf

Uhl-Bien, M. (2003). Relationship development as a key ingredient for leadership development. In Murphy, S. \& Riggio, R. (Eds.), The future of leadership development (pp. 129-147). Mahwah, NJ : Lawrence Erlbaum Associates.

Wang, H., Law, K., Hackett, R., Wang, D., \&Chen, Z. (2005). Leader-member exchange as a mediator of the relationship between transformational leadership and followers' performance and organizational citizenship behavior. Academy of ManagementJ ournal, 48(3), 420-432. DOI: 10.5465/AMJ .2005.17407908 
Athabasca University $\mathbf{Z}$

(c) $\underset{\mathrm{EY}}{\mathrm{C}}$ 